\title{
PRESENÇA DE FORMAS FILOSÓFICAS MEDIEVAIS NA FENOMENOLOGIA NASCENTE: O CASO DE EDITH STEIN
}

\author{
Presence of Medieval Philosophical Forms in the Nascent Phenomenology: The Case of Edith Stein
}

Presencia de Formas Filosóficas Medievales en la Fenomenología Naciente: El Caso de Edith Stein

JUVENAL SAVIAN FILHO

\begin{abstract}
Resumo: Se para a fenomenologia de Husserl o papel do pensamento medieval não é essencial, inteiramente diferente é o caso da filosofia madura de Edith Stein, por ela intitulada filosofia do ser, em uma conjunção explícita de fenomenologia e metafísica. Iniciando, então, por um breve estudo da relação entre Husserl e formas medievais do pensamento, este artigo concentra-se no caso específico de Edith Stein e sua recepção de autores como Anselmo de Cantuária e Tomás de Aquino, entre outros, concluindo pela sua investigação sobre o que torna possível a afeccionabilidade ou a afectibilidade, quer dizer, a condição de possibilidade da síntese passiva.
\end{abstract}

Palavras-chave: Fenomenologia - Metafísica - Síntese Passiva - Husserl - Edith Stein

Abstract: If for Husserl's Phenomenology the role of medieval thought is not essential, it is entirely different from Edith Stein's mature philosophy, which she calls philosophy of being, in an explicit conjunction of Phenomenology and Metaphysics. So, starting by a brief study on the relationship between Husserl and medieval forms of thought, this article focuses on the specific case of Edith Stein and her reception of authors such as Anselm of Canterbury and Thomas Aquinas, among others, concluding by her investigation on what makes affectionability or affection possible, that is, the condition of possibility of passive synthesis.

Keywords: Phenomenology - Metaphysics - Passive Synthesis - Husserl - Edith Stein

Resúmen: Si para la fenomenología de Husserl el papel del pensamiento medieval no es esencial, completamente diferente es el caso de la filosofía madura de Edith Stein, por ella intitulada filosofía del ser, en una conjunción explícita de fenomenología y metafísica. Empezando, entonces, por un breve estudio de la relación entre Husserl y formas medievales de pensamiento, este artículo se centra en el caso específico de Edith Stein y su recepción de autores como Anselmo de Cantuaria y Tomás de Aquino, entre otros, concluyendo por su investigación sobre lo que hace posible la afeccionabilidad o la afectibilidad, es decir, la condición de posibilidad de la síntesis pasiva.

Palabras-clave: Fenomenología - Metafisica - Síntesis Pasiva - Husserl - Edith Stein

\section{Introdução}

Não é novidade que há grandes semelhanças entre elementos desenvolvidos por formas medievais de pensamento e elaborações feitas na fenomenologia ${ }^{1}$. Todavia, no que concerne especificamente à fenomenologia de Husserl, a relação com filosofias medievais é um tema que ainda demanda esclarecimentos. Afinal, a despeito de se ter tornado comum afirmar, por exemplo, que o pai da fenomenologia inspirou-se no pensamento medieval ao estabelecer certos aspectos do método fenomenológico (eminentemente a concepção da consciência como intencionalidade), Husserl não se dedicou a um estudo sistemático de formas medievais de pensamento nem recebeu influência direta delas, ou, menos ainda conservou alguma dessas formas em seu trabalho filosófico.

Aliás, se Husserl realmente tivesse estudado autores medievais, não teria emitido certos juízos histórico-filosóficos claramente equivocados nas vagas referências que faz aos medievais (por exem-

1 Diversos são os estudos que exploram essas semelhanças, mas, apenas para citar um título já traduzido em português, veja-se De Muralt, A. (1998). Metafisica do fenômeno: as origens medievais e a elaboração do pensamento fenomenológico. Trad. Paula Martins. São Paulo: Editora 34, 1998. plo, associando-os a um realismo ingênuo). Mesmo Martin Heidegger, que - muito mais do que Husserl - estudou sistematicamente alguns autores medievais, apenas com muita dificuldade pode ser considerado um pensador cuja filosofia sofreu alguma influência real de formas filosóficas elaboradas na Idade Média, até porque sua singular hermenêutica talvez não tenha sido justa com os pensadores interpretados ${ }^{2}$.

No tocante especificamente à intencionalidade e ao papel do pensamento medieval na formação da fenomenologia husserliana, convém certamente abandonar os clichês historiográficos, porque, em primeiro lugar, Husserl nunca reivindicou uma filiação a nenhum autor medieval, mas apenas fez uma ou outra associação, rara e brevíssima, entre a relação intencional (relação entre o conhecimento e o objeto) e a concepção da inexistência, inhabitação ou pericorese intencional/mental de um objeto tal como Franz Brentano dizia encontrar nos "escolásticos”3; e, em segundo lugar - e mais importante

2 Cf. Boulnois, O. (1999). Heidegger, l'onthothéologie et les structures médiévales de la métaphysique. Le Philosophoire 3, n. 9, pp. 27-55.

3 Cf., por exemplo, Husserl, E. (1968). Logische Untersuchungen. Tübingen: M. Niemeyer, v. II-1, p. 366-369. 
- porque, mesmo que tenha havido uma teoria medieval da intencionalidade tal como compreendida por Brentano e entendida por Husserl, parece mais coerente pensar que a intencionalidade husserliana não coincide com tal teoria, uma vez que, se houve uma teoria que tomava a intencionalidade como um dado, então ela foi de saída radicalmente diferente da "teoria" husserliana, uma vez que em Husserl a intencionalidade é algo a ser esclarecido, e não um ponto de partida ou um porto seguro a partir do qual se constrói uma filosofia. Em Husserl, a intencionalidade é, antes, o horizonte em vista do qual se põe em marcha sua atividade filosófica, uma vez que ele visa explicitar o a priori da correlação ou a correlação transcendental entre o mundo e a subjetividade, entendida não mais como a correlação entre sujeito e objeto no interior do mundo, e sim como a relação entre o conhecimento e o objeto reduzido, quer dizer, entre o conhecimento imanente e a transcendência posta pela imanência mesma. Por conseguinte, se a intencionalidade de Brentano, seguindo algum trabalho medieval, toma a intencionalidade como um dado, sua intencionalidade pareceria mesmo estéril para a filosofia ${ }^{4}$, uma vez que, além de não fazer mais do que repetir o que teria sido a "intencionalidade escolástica" por ele pretensamente continuada, ela também não despertaria interesse do ponto de vista da interlocução com o pensamento moderno, pois não põe o problema radical do conhecimento ou das condições de possibilidade do conhecimento objetivo.

Inteiramente diferente, porém, é o caso de Edith Stein no contexto da fenomenologia nascente.

\section{Edith Stein e o pensamento medieval}

A filosofia de Edith Stein é peculiar e permite conhecer outro tipo de relação entre a fenomenologia husserliana e formas medievais de pensamento. Não se trata, no seu caso, de buscar "raízes" medievais de sua filosofia (pois suas raízes estão, em primeiro lugar, no método husserliano), mas de entender seu projeto de acionar filosofias medievais e combiná-las com a fenomenologia de seu mestre. O pensamento steiniano é, assim, uma das fontes mais adequadas para estudar a presença realmente operante de formas filosóficas medievais na fenomenologia e na Contemporaneidade em geral, bem como para aquilatar o sentido dessa presença, para além de uma simples evocação genealógica ou arqueológica.

Impõe-se de saída, obviamente, buscar as justificativas de Edith Stein para a conjugação entre fenomenologia e pensamento medieval ou, mais explicitamente, entre fenomenologia e metafísica, uma vez que tal conjugação apresenta-se como algo no mínimo esdrúxulo, para não dizer descabido se se tem em mente que, em contexto husserliano, o primado radical da epistemologia parece obrigar a considerar a passagem à metafísica uma infidelidade às exigências da redução fenomenológica e da teoria da constituição.

4 Cf. Moura, C. A. R. (1989). Crítica da razão na fenomenologia. São Paulo: EDUSP \& Nova Stella, p. 35.
Antes, porém, de abordar as razões de Edith Stein, convém ilustrar o tipo de relação mantida por ela com o pensamento medieval. Para tanto, evocar-se-ão aqui dois exemplos precisos: (i) a reelaboração steiniana do assim chamado argumento ontológico anselmiano; (ii) a interpretação steiniana da concepção tomasiana da abstração:

(i) Edith Stein assimila o argumento dito ontológico de Santo Anselmo, pretendendo, no entanto, "melhorá-lo", pois, no seu dizer, seu próprio argumento tem melhor funcionamento ao estabelecer uma compreensão elementar de Deus mais clara. Com efeito, em Ser finito e eterno III, 12, a filósofa pretende evitar as dificuldades que implicava a definição anselmiana de Deus como "aquilo de que nada de maior pode ser pensado" e propõe tomar a concepção tomasiana de Deus como "aquilo cuja essência é existir" (id cujus essentia est esse / das dessen Wesen das Sein ist). Tal noção seria melhor por permitir distinguir entre os entes finitos, cuja essência não pode ser realmente separada de sua existência (embora tal essência e tal existência possam ser pensadas separadamente), e o primeiro ente, Deus, cuja essência não pode nem mesmo ser pensada à parte de sua existência, pois, se afastarmos pelo pensamento seu existir, não restará nada. Edith Stein, como se vê, assimila e reelabora o argumento anselmiano. Ela não o altera essencialmente, pois o argumento continua a inferir a realidade do ente absoluto com base na ideia do ente absoluto, mas opera com uma ideia mais clara do ente absoluto, a fim de evitar a crítica tomasiana ou "empirista", segundo a qual o argumento de Anselmo opera uma passagem injustificada da lógica para a ontologia. A propósito, Edith Stein acerta na mudança da definição do ente absoluto - independentemente de sua exegese de Anselmo ser ou não correta - porque, no modo como o argumento é montado, cair-se-ia de fato em uma falácia se se procedesse do pensamento para a coisa. Ora, como o argumento steiniano se restringe a uma essência que é seu próprio existir e aplica-se somente a Deus (indo, portanto, da essência ao existir), então ele é válido, além de fornecer finalmente a razão de Deus ser o "maior" e o "mais perfeito" dos entes: a sua essência é o seu existir, razão pela qual ele não pode ser pensado separadamente de seu existir ${ }^{5}$;

(ii) engana-se, porém, quem ler a expressão “crítica tomasiana ou 'empirista”, registrada acima, e pensar que o pensamento de Tomás de Aquino é interpretado por Edith Stein como um tipo de empirismo ou de filosofia que pressupóe uma teoria do conhecimento de acordo com a qual o objeto externo determinaria ou causaria a atividade de conhecer. O caráter, digamos, "empirista” da crítica tomasiana ao argumento ontológico justifica-se por sua exigência de ir da coisa para o pensamento, mas isso não quer dizer que o pensamento tomasiano seja uma forma

5 Para um estudo detalhado da compreensão steiniana do argumento de Anselmo, ver: Redmond, W. O argumento ontológico de Edith Stein $T Q$ - Teologia em Questão - Revista de Teologia: O pensamento de Edith Stein (Escritos críticos) 30 (2016), Ano XV, Taubaté: Faculdade Dehoniana, pp. 73-100. 
de empirismo ou de compreensão do intelecto ou da consciência como tabula rasa. A esse respeito, no texto A fenomenologia de Edmund Husserl e a filosofia de Santo Tomás de Aquino, Edith Stein insiste no que ela considera uma coincidência de Tomás com a fenomenologia, quer dizer, a defesa de que todo conhecimento humano natural adquire-se por meio de uma elaboração intelectual de um material sensível: o intellectus dividens et componens da filosofia de Tomás de Aquino realiza uma atividade que se exprime, em fenomenologia, como o prescindir de tudo aquilo que corresponde à coisa de modo apenas acidental; trata-se de uma orientação da mirada para o que corresponde à coisa material como tal, ao que pertence à ratio da coisa material. A abstração tomasiana não seria, portanto, uma abstração de tipo indutivista. Seria simplificar demais e trair o pensamento de Tomás de Aquino conceber o dividere e o componere como conclusões da indução e mesmo da dedução no sentido das ciências naturais empíricas e das formas tradicionais dos silogismos. Justamente por essa exegese singular do pensamento de Tomás de Aquino, e mesmo sem ser historicamente uma adepta do tomismo transcendental, Edith Stein também podia defender o reverso da mesma moeda: Husserl era em certa medida tomasiano, uma vez que ele aceitaria sem problema, segundo o quadro da exegese steiniana de Tomás, que todo conhecimento começa com os sentidos. Assim, ainda que Tomás seja considerado "pré-crítico" do ponto de vista da historiografia filosófica, seu pensamento, na leitura de Edith Stein, não deixa de proceder a uma crítica da razão quando põe em questão o papel do intelecto na produção do conhecimento. Seja como for, o Tomás de Aquino de Edith Stein não é o do objetivismo ingênuo que Husserl pensava ser, tampouco o do empirismo indutivista como queriam alguns neotomistas ou neoescolásticos do tempo de Edith Stein.

\section{Razões para a conjugação steiniana da fenomenologia com metafísicas medievais}

Esses exemplos permitem enfatizar que o pensamento medieval não apenas "inspira" Edith Stein $^{6}$, mas é por ela presentificado e tomado como forma operante e válida em contexto fenomenológico. A assimilação do argumento de Anselmo é certamente mais pontual e menos essencial para o pensamento maduro de Edith Stein do que a associação com o pensamento tomasiano, que, a partir da obra Potência e ato, torna-se vital para a filósofa: por exemplo, o par conceitual ato/potência, tal como explorado por Tomás de Aquino, permitirá a Edith Stein construir a filosofia do ser que ela propõe como continuação da fenomenologia ${ }^{7}$. Não por acaso ela adota o par ato/potência como condições fundamentais do ente: no limite, é a questão da

\footnotetext{
6 O léxico da "inspiração", com suas variantes ("modelo", "ideal", "exemplo", "guia", "mestre" etc.) é usado em geral pelos comentadores para exprimir o tipo de influência de Tomás de Aquino sobre Edith Stein, indicando-se os novos horizontes filosóficos (eminentemente metafísicos) abertos por Tomás a Edith. Ele também é empregado, com grande frequência, para defender que a filósofa teria se tornado neotomista depois de sua conversão religiosa, o que todavia não parece ser o caso.

7 Muitos elementos provindos de vários outros autores medievais são também assimilados por Edith Stein, entre eles Agostinho, Boécio, Dionísio
}

existência temporal, marca central da experiência humana, que lhe permite pôr em diálogo direto o pensamento escolástico com a fenomenologia de Husserl e com o primeiro Heidegger, cuja influência é reconhecida pela própria Edith Stein no prefácio de Potência e ato.

Impõe-se, no entanto, a necessidade de justificar em termos fenomenológicos a abertura da investigação ou da filosofia fenomenológica a uma investigação ou filosofia de impostação nitidamente metafísica. Não oferecer essa justificativa significaria expor-se ao risco de dever assumir que talvez Edith Stein tenha abandonado a fenomenologia e assumido outro estilo filosófico (no caso, o neotomismo). Seus textos, porém, transparecem clara e evidentemente a sua continuidade com a fenomenologia de Husserl. Como, então, Edith Stein exprime o sentido da sua conjugação da fenomenologia com formas filosóficas de orientação metafísica?

Na obra Potência e ato, escrita por Edith Stein em 1931-1935 e publicada apenas em 1998, encontram-se duas passagens que concorrem para explicitar as razões da filósofa: por um lado, há uma explicação da própria filósofa para o seu seguimento de Tomás de Aquino (explicação que vale certamente também para os os outros autores medievais assimilados por Edith Stein, uma vez que sua atitude é sempre a mesma); por outro lado, há uma tentativa, discreta e no entanto bastante instigante, de levar a investigação husserliana a um passo adiante em relação ao ponto ao qual chegara Husserl, ponto este em que, de dentro da imanência, seria solicitada a afirmação da transcendência como efetividade onticamente independente da consciência. Esse ponto articularia, por conseguinte, a investigação fenomenológica com a investigação metafísica de caráter tomasiano.

Com efeito, tendo anunciado no Prólogo de Potência e ato sua intenção de produzir uma "filosofia do ser" que compusesse a fenomenologia com o pensamento de Tomás de Aquino, Edith Stein justifica-se, em resumo, dizendo que seu trabalho era filosófico, e não um trabalho típico das Ciências do Espírito: diante de um pensamento, a atividade das Ciências do Espírito consiste em estudar a articulação das razões internas desse pensamento, ao passo que a atividade da Filosofia consiste em compreender por que um pensador articulou suas razões na maneira como as articulou. Em Filosofia, buscar-se-ia chegar à experiência mesma que suscitou um pensamento, vivenciar suas causas, ser impressionado por elas e decidir-se por elas ou contra elas (seguindo o pensador estudado ou procurando outro caminho). É nesse nível que se pode pretender uma apropriação das razões de um filósofo, uma composição com elas ou ainda a recusa delas. Interessar-se apelas pela "lógica" ou "estrutura interna" de um pensamento significaria mantê-lo à distância como alvo de um interesse não propriamente filosófico (um interesse histórico, sociológico ou outro).

Pseudoareopagita e Duns Escoto. A respeito da forte influência do escotismo no pensamento steiniano maduro (embora Edith Stein nunca tenha lido propriamente Duns Escoto), ver: Alfieri, F. (2016). A presença de Duns Escoto no pensamento de Edith Stein: a questão da singularidade. Trad. Juvenal Savian Filho e Clio Francesca Tricarico. São Paulo: Perspectiva. 
Dessa perspectiva, a primeira justificativa de Edith Stein parece estar no fato de ela pretender que sua experiência coincide com a experiência de Tomás de Aquino tal como ele a exprime em seus textos. A experiência de Edith Stein se vê retratada no modo como Tomás de Aquino registra a sua própria experiência ou a sua filosofia. Por essa coincidência profunda, então, parecia "natural" a Edith Stein dedicar-se a construir uma filosofia do ser de matriz fenomenológico-tomasiana. O caráter fenomenológico dessa filosofia do ser vinha, por sua vez, do fato de Edith Stein ter sido formada por Edmund Husserl e de ela assumir-se como uma seguidora de seu mestre. Assim, no limite, a prioridade de sua filosofia do ser é dada à "consciência do ser" (genitivo objetivo ${ }^{8}$ ). É como fenomenóloga que ela busca uma filosofia do ser de inspiração tomasiana, ainda que, como ela mesma reconhece, encontrar tal filosofia significava ir além da fenomenologia.

A bem da verdade, mais do que extrapolar a fenomenologia, Edith Stein pretendia levá-la às últimas consequências, pois, no terreno dessas últimas consequências, no qual Husserl não pudera adentrar (dado seu recorte estritamente epistemológico), Edith Stein via a base para a conexão com uma investigação de caráter metafísico. Trata-se de uma fronteira na qual a imanência mesma da consciência parece solicitar a afirmação da independência ôntica da efetividade (a realidade). Afirmada tal independência (que já fora obtida, aliás, por meio da descrição da intersubjetividade), o par conceitual tomasino ato/potência permitiria descrever com mais clareza a estrutura última da efetividade mesma. É o que parece possível obter do trecho registrado no fim do "Excurso sobre o idealismo transcendental”, aposto quase ao final da obra $P_{O}$ tência e ato.

Com efeito, ao retomar o tema inicial do mencionado Excurso, o tema da sensação, Edith Stein serve-se de um exemplo bastante simples: algo surge diante de meu olhar e desaparece antes que eu o perceba ou o retenha. Depois surge de novo e tenho a ocasião de examiná-lo. Vejo que é uma flor jogada ao vento. $\mathrm{O}$ exemplo mostra que o emergir de algo me faz reagir involuntariamente (levanto os olhos sem decidir por esse ato), para só depois agir voluntariamente (perceber e examinar). Interessa a Edith Stein a natureza involuntária da reação, porque essa natureza mostra haver uma emergência/ aparição (Auftreten) de dados da sensação como dados na fronteira da imanência e da transcendência (dados de consciência imanente-transcendentes: immanent-transzendenter Bewusstseinsdater) que permanecem ininteligíveis ou impossíveis de elucidar na reflexão puramente imanente.

Dito de outra maneira, Edith Stein parece identificar um limite na análise do idealismo transcendental de Husserl, pretendendo ir além desse limite. Recorde-se que, segundo Husserl, se se dá

8 Não é por acaso que o subtítulo de Ser finito e eterno, sua obra de maturidade, nascida com base no projeto da obra Potência e ato, seja "Ensaio de uma ascensão ao sentido do ser". A expressão sentido do ser garante a preeminência da abordagem fenomenológica na filosofia steiniana do ser ou a preeminência da abordagem do ser como "ser conhecido" (e não ingenuamente pressuposto como um ser diante do qual a consciência se põe como polo passivo). atenção à experiência na qual a transcendência da realidade da coisa ou do mundo de coisas se impõe à consciência (e que é o fundo da orientação natural), percebe-se que: (i) a transcendência do ente real não pode ser confundida com um simples sentido intencional (correlato de um modo subjetivo de apreensão) ou com uma compreensão, porque a experiência que doa originariamente o mundo é a experiência de ser afetado ou de receber afecção; (ii) esse ser afetado ocorre antes da doação de sentido e fora dela; (iii) a essência da transcendência consiste no seu manifestar antes de qualquer intencionalidade e mesmo sem ela; (iv) o que se doa antes da intencionalidade - e é mesmo sua condição de possibilidade ou sua possibilidade transcendental - é a síntese passiva originária da consciência do tempo; (v) mas essa síntese - que é a mais originária de todas e que gera e sustenta a possibilidade de toda visada intencional - repousa sobre a afecção ou a afeccionabilidade própria da afecção originária em sua atualidade. Em outras palavras, repousa na possibilidade ou na potência da afecção que garante e suporta a afecção originária em ato ${ }^{9}$. Mas aqui Edith Stein parece ver o limite da fenomenalidade de Husserl; seria esse o ponto de originariedade diante do qual para ou estaciona o questionamento husserliano. Edith Stein parece querer justamente ir além desse ponto.

A filósofa parece querer ir além desse limite porque ela pergunta pelo que torna possível a afeccionabilidade ou a afectibilidade, quer dizer, em resumo, pela condição de possibilidade da síntese passiva. Esse "projeto" é o que parece explicar o porquê de Edith Stein dizer que no movimento involuntário há um saber vivencial/experiencial (Erfahrungswissen) a respeito do corpo (Körper), com sua posição, comportamento e movimentos, saber esse que leva o indivíduo a perceber-se como corpo vivo (Leib), união estreita entre materialidade e vida sensível/psíquica: vemo-nos como mais uma coisa entre outras (Körper), mas também nos vemos como seres diferentes, espirituais (Leib). Essa diferença é explicada por Edith Stein em termos da afecção que se revela no corpo psicofísico: somos preparados para ter afecções que não apenas manifestam um estímulo ou uma estimulação do corpo, mas que também têm uma função objetiva, a de atualizar ou trazer a ato a função específica do conhecimento dos sentidos ou a afeccionabilidade. A afeccionabilidade ou potência de receber afecção é a condição da sensação; ela permite a função dos sentidos. Ela é, por conseguinte, o elo com o mundo das coisas independente onticamente, uma vez que o saber sobre o próprio corpo vivo se faz pelos nexos envolvendo o corpo e a doação das coisas na percepção. É o vê-las como existentes e diferentes de mim, assim como vejo outros corpos humanos como existentes e diferentes de mim, que me dá o meu saber sobre mim mesmo. A doação das coisas é valorizada, então, tanto quanto a experiência intersubjetiva; Edith Stein não admite a sua irracionalidade ou o seu

9 Cf. Lavigne, J.-F. (2015). En deçà du transcendental: les conditions pré-phénoménales de la vie transcendentale. Metodo. International Studies in Phenomenology and Philosophy. Special Issue, n. I, 1, p. 83-102. 
caráter de "resíduo irracional", como, no seu dizer, pensava Husserl. Antes, sua inteligibilidade é garantida pela afectibilidade; e conhecer não deixará de significar conhecer-se a si mesmo.

O risco dessa "radicalização" da fenomenologia e da conexão com o mundo exterior parece estar, obviamente, em reabrir espaço para a filosofia da representação de tipo empirista que concebe a consciência como tabula rasa. No entanto, a afectibilidade e a autodoação das coisas, condição para a doação de sentido pela consciência, não significa, para Edith Stein, algo como uma "heteronomia da afecção”. A conexão dos dados da sensação e das espécies sensíveis com o mundo exterior ou a ideia de que as coisas "caem" sob os sentidos significa que o sujeito é objetivamente orientado (gegenständlich gerichtetes), aberto ao objeto como sujeito intelectual. Cada intuição não é meramente sensível: o material sensível aparece como aquilo que preenche uma “estrutura” formal, porém não como algo elaborado por formas estruturais, tais como as formas da sensibilidade e as categorias do entendimento em termos kantianos, mas como aquilo cuja presença fornece um sentido para cuja "leitura" ou "interpretação” o sujeito está preparado.

Ainda, uma forma de coisa corresponde a certas formas de ato (Dingformen/Aktformen). A rigor, a consciência não é formada "de fora", mas é estimulada por coisas de fora. Tudo se resolve no presente ou na vida atual do sujeito, segundo Edith Stein, inclusive a recordação e a fantasia, salvo que nesses atos a crença na existência não é implicada. Tal crença é sim implicada e legítima na percepção direta. De certa maneira, na visão de Edith Stein, dizer isso é uma consequência da própria redução que punha tal crença fora de circuito. É também encontrar o pensamento tomasiano, que, sem ser ingenuamente objetivista, dá prioridade à função objetiva de atualizar a função específica do conhecimento dos sentidos ou a afeccionabilidade, ao mesmo tempo em que também prioriza o subjetivismo que reconhece a função do intelecto de produzir conhecimento como elaboração propriamente intelectual de um material sensível. Dessa perspectiva, conhecer é não apenas conhecer a si mesmo, mas é rigorosamente também conhecer a alteridade dos objetos.

\section{À guisa de conclusão}

Parece possível dizer que, se em Husserl o papel do pensamento medieval não é essencial e talvez não passe de uma evocação vaga e inteiramente dispensável, o mesmo não se pode pensar em relação à filosofia de Edith Stein, cuja vinculação com formas filosóficas desenvolvidas na Antiguidade Tardia e na Idade Média é essencial em sua fase madura.

Se por um lado essa importância é justificada pela coincidência dos conteúdos experimentados por Edith Stein e pelos medievais, por outro lado ela também pretende ser justificada pelo fato de o pensamento medieval aparecer como uma forma de continuar o projeto fenomenológico husserliano, abrindo um caminho que levaria à investigação de características essenciais dos objetos. Agora, com elementos medievais, Edith Stein acreditava poder descrever a experiência humana como a experiência de seres que são preparados para ter afecções que não apenas manifestam um estimulação do corpo, mas que também têm uma função objetiva, a de atualizar ou de trazer a ato a função específica do conhecimento dos sentidos ou a afeccionabilidade. Ora, não haveria afeccionabilidade se não houvesse objetos externos que afetem a subjetividade na síntese passiva. Em outras palavras, não haveria afeccionabilidade se não houvesse entes onticamente independentes, algo defendido com clareza pelas metafísicas medievais acionadas por Edith Stein.

\section{Referências}

Alfieri, F. (2016). A presença de Duns Escoto no pensamento de Edith Stein: a questão da singularidade. São Paulo: Perspectiva.

Boulnois, O. (1999). Heidegger, l'onthothéologie et les structures médiévales de la métaphysique. Le Philosophoire 3, n. 9, pp. 27-55.

De Muralt, A. (1998). Metafísica do fenômeno: as origens medievais e a elaboração do pensamento fenomenológico. São Paulo: Editora 34.

Husserl, E. (1968). Logische Untersuchungen. Tübingen: M. Niemeyer.

Lavigne, J.-F. (2015). En deçà du transcendental: les conditions pré-phénoménales de la vie transcendentale. Metodo. International Studies in Phenomenology and Philosophy. Special Issue, n. I, 1, p. 83-102.

Moura, C. A. R. (1989). Crítica da razão na fenomenologia. São Paulo: EDUSP \& Nova Stella.

Juvenal Savian Filho é Professor do Departamento de Filosofia da Universidade Federal de São Paulo. Coordenador do Grupo de Pesquisa Edith Stein (Unifesp) e do Grupo de Trabalho Edith Stein e o Círculo de Gotinga (ANPOF). Email: jsfilho@alumni.usp.br

Recebido em 23.01.2018 Aceito em 02.08.2018 